\title{
New practical MS/MSE degree program with concentration in optics and photonics technology
}

John Dimmock, Anees Ahmad, Stephen Kowel

John O. Dimmock, Anees Ahmad, Stephen T. Kowel, "New practical MS/MSE degree program with concentration in optics and photonics technology," Proc. SPIE 2525, 1995 International Conference on Education in Optics, (13 October 1995); doi: 10.1117/12.224029

Event: SPIE's 1995 International Symposium on Optical Science, Engineering, and Instrumentation, 1995, San Diego, CA, United States 
New practical MS/MSE degree program with concentration in optics and photonics technology

John O. Dimmock ${ }^{1}$, Anees Ahmad ${ }^{2}$ and Stephen T. Kowel ${ }^{3}$

University of Alabama in Huntsville Huntsville, AL 35899

\begin{abstract}
$\underline{\text { ABSTRACT }}$
An interdisciplinary Masters Program with a concentration in Optics and Photonics Technology has been developed under the U.S. Manufacturing Education and Training Activity of the Technology Reinvestment Project. This development has been a collaboration between the University of Alabama in Huntsville, Alabama A\&M University, Northwest Shoals Community College, the NASA Marshall Space Flight Center, the U. S. Army Missile Command, Oak Ridge National Laboratory, Advanced Optical Systems Inc., Dynetics, Inc., Hughes Danbury Optical Systems, Inc., Nichols Research and Speedring Inc. These organizations as well as the National Institute for Standards and Technology and SCI, Inc. have been participating fully in the design, development and implementation of this program. This program will produce highly trained graduates who can also solve practical problems, and includes an on-site practicum at a manufacturing location.

The broad curriculum of this program emphasizes the fundamentals of optics, optical systems manufacturing and testing, and the principles of design and manufacturing to cost for commercial products.

The MS in Physics and MSE in Electrical Engineering Degrees with concentration in Optics and Photonics Technology are offered by the respective UAH academic departments with support from and in consultation with a Steering Committee composed of representatives from each of the participating organizations, and a student representative from UAH.
\end{abstract}

Keywords: $\quad$ education, optics, masters, technology

\title{
2. ORIGIN AND MOTIVATION
}

The origins of the new Master's of Science and Master's of Science in Engineering program with Concentration in Optics and Photonics Technology go back to early 1993 when a group of scientists and engineers representing mostly Huntsville area government, industry and academic organizations started meeting to discuss the possibility of forming an alliance focussed on defense conversion and the possible commercialization of their largely defense and government oriented technologies and business strategies. At that time the group consisted of representatives of The University of Alabama in Huntsville (UAH), Northwest Shoals Community College, the NASA Marshall Space Flight Center (MSFC), the U. S. Army Missile Command (MICOM), the Army Space and Strategic Defense Command (SSDC), the Oak Ridge National Laboratory (ORNL) and about a dozen, mostly local, companies involved in optical technology. This group shared a common objective in working together on defense conversion and the pursuit of dual-use technologies for the benefit of all participants.

The result of these early discussions was an agreement, reached in May of 1993, to form the Alliance for Optical Technology. The final Memorandum of Agreement, which was effected on March 16, 1994, stipulates that the signatory organizations "...desire to form a strategic alliance to advance the development and transfer of technologies in the interest of enhancing the global competitiveness of the industrial members while facilitating the effectiveness of the public sector members

\footnotetext{
${ }^{1}$ Center for Applied Optics

${ }^{2}$ Optical Science and Engineering Program and Center for Applied Optics

${ }^{3}$ Department of Electrical and Computer Engineering
} 
in meeting their mission objectives particularly in the area of strengthening the technological competitiveness of the United States." The stated purpose of the Alliance is for "...coordinating ... precompetitive activities in optical technology, sharing controlled access to each other's facilities, ..., exchanging and/or sharing personnel resources ..., providing advanced education and training in applied optical technology and manufacturing, seeking funds for cooperative projects, identification of common technical and manufacturing deficiencies, pooling, ... internal and external information, providing controlled access to the technology of Alliance members, providing links to new market sectors, and providing a shared electronic design system for project support."

Of these noble and ambitious objectives, the one that the Alliance decided to pursue first was that of developing an advanced education and training program in applied optical technology and manufacturing. A proposal to develop a new Practice-oriented Master's in Optics program was submitted to the U. S. Manufacturing Education and Training Activity of the Technology Reinvestment Project (TRP) in July 1993. It was selected for funding in the fall of 1993 and the award was made in March 1994. The proposal stipulated that "Industry and government organizations will participate fully in the design, development and implementation of this program. The program will be designed to produce highly-trained graduates, who have an optimum combination of skills in the areas of manufacturing engineering, science, management and business-practices, and who can solve practical problems. The program will include an on-site practicum at a manufacturing industry. The program will enable the defense workforce and industry transition to commercial manufacturing, enhance their competitiveness in global marketplace, and expand the US job base and economy." Again, very noble and ambitious objectives.

\section{PROGRAM DEVELOPMENT}

A Steering Group for the development and implementation of the program was set up in the fall of 1993 consisting of representatives of a subset of the Alliance membership and additional university faculty from UAH and Alabama A\&M University (AAMU). A student representative was added in the fall of 1994 when the first class was matriculated. The current project team is indicated in Table I with a total of 45 representatives on the Steering Committee. This would be completely unwieldy should everyone show up at any one meeting. Most Steering Committee meetings consist of about fifteen representatives with all sectors of the project team community reasonably well represented.

This group worked through April 1994 to define a program and curriculum which met their diverse requirements and expectations. It was decided that the program would be offered with two tracks under existing UAH master's degrees with special concentrations: one as a Master's in Science with Concentration in Optics and Photonics Technology under the UAH Physics Department and the other as a Master's of Science in Engineering with Concentration in Optics and Photonics Technology under the UAH Electrical and Computer Engineering Department. A sense of the challenge of reconciling very disparate viewpoints is captured in the UAH Physics Department internal memorandum of February 7, 1994, recommending approval of the program "on a trial basis". This memorandum states, in part, that "... there was some concern ... that the proposed degree program did not have sufficient core physics graduate courses." The recommendation was made that, with the addition of pairs of electives from the physics core program, the program would be satisfactory provided that it "... be viewed as an 'experimental' terminal Masters program with an emphasis on a particular specialty. While this is a significant departure from our current program, the success of the program should provide our department with a means of addressing (through a reexamination of our graduate program) the national concern that many physics graduates are lacking the necessary qualifications demanded by modern industry (see Physics Today, January 1994). The Graduate Committee will examine the success of the program after 2-3 years and in the meantime our current program will be reviewed. Should the optics MS degree prove a success, the question of such a graduate program based on focused areas of specialization is appropriate and ... (should) ... be seriously considered..."

The program was also accepted on a trial basis by the UAH Department of Electrical and Computer Engineering and the two departments worked together and with the Center for Applied Optics and the Steering Group to formulate the curriculum and course content for the new courses that needed to be developed.

\section{PROGRAM STATUS/CONTENT}

Table II indicates the resultant Curriculum Requirements. Table III gives a Typical Course Schedule although the program 
also supports alternative and nontraditional schedules. Four new courses were developed specifically for this program. These are the three listed in Table II under Optics Design and Manufacturing Technology, namely "Optics and Photonics System Design", "Optomechanical Design and Manufacturing" and "Optical Fabrication and Testing"; and the "Integrated Production and Process Design" course under Engineering Management. Syllabi for these courses are included in Tables IV - VII. As of this writing most of the students in the program have completed the first two semesters, taking the first two of the new courses, and report that the program is going reasonably well from their perspectives. They have not taken either of the last two new courses, scheduled for the Fall of 1995.

In the early planning stages it was decided that the degree should require a practicum/thesis and that these would be conducted at non-university locations. A number of the organizations involved in the development of the program volunteered to offer support for students pursuing their practicum at their locations. The list of such opportunities is given in Table VIII. The students are now engaged in their on-site practicum summer thesis work in accordance with Table III.

\section{LESSONS LEARNED} for others.

These lessons may not be all that surprising to those who have developed new curricula in the past yet they may be useful

First, it was an interesting challenge to develop and get Steering Committee agreement on a new curriculum with as diverse a group as we had, but it can be done. This took about three months of fairly steady effort. Initially there was a significant difference of viewpoint between the academic and the government/industry representatives with the academic representatives stressing fundamentals and the industry stressing practical training. What resulted, of course, was a mix.

Second, it takes a considerable amount of time to get a new set of courses and curriculum approved by the academic organizations involved once they were approved by the Steering Committee. This also took about three months.

Third, even with reasonably extensive advertising, it takes time for the student community to realize that there is a new program available. All reasonable avenues for advertising should be pursued and a process should be established to ensure that all inquiries and applications get communicated promptly to the program office. A considerable amount of time should be set aside by the program office to discuss the program with prospective students.

Fourth, nearly every prospective student either requires or expects financial support. This needs to be budgeted and a process established to determine who gets supported. A time-line for this needs to be established and communicated in advertising and to the prospective students.

\section{ACKNOWLEDGEMENTS}

Obviously the development and implementation of this program has required the support and participation of many individuals and organizations. First, we would like to acknowledge Jeff Bennett, U. S. Army Missile Command; Jim Bilbro, NASA Marshall Space Flight Center; Gordon Emslie, Chairman of the UAH Physics Department; Darell Engelhaupt, UAH Center for Applied Optics; Dick Hartman, Advanced Optical Systems; Gary Kamerman, Teledyne Brown Engineering; Neil Mohon, Dynetics; and David Olson, Hughes Danbury Optical Systems; who, among other members of the Alliance for Optical Technology, were very effective in the initial definition and development of the program. Second, we would like to thank the NASA Marshall Space Flight Center, the U. S. Army Missile Command, the Oak Ridge National Laboratory, Advanced Optical Systems, Inc., Dynetics Inc., Hughes Danbury Optical Systems, Nichols Research, the National Institute for Standards and Technology, SCI Inc., and Speedring for offering support for the student onsite practicum thesis projects. Third, we would like to thank Bob Berinato, Dynetics, Inc. for his continued support and for teaching several of the Optomechanical Design and Manufacturing classes. Classes were also taught by Ned Bragg, OETC, Inc.; David Pollock, UAH; and Jim Spann, NASA/MSFC. Finally we would like to acknowledge support of the Technology Reinvestment Project, and thank John Jennings, ARPA, and John Carlisle and Sally Little, NASA/MSFC, for their interest and support. 


\section{MS/MSE Concentration in Optics and Photonics Technology}

\section{Project Team}

Academic Institutions

University of Alabama in Huntsville

Alabama A\&M University

Northwest Shoals Community College

Industrial Affiliates

Advanced Optical Systems

Dynetics Inc.

Hughes Danbury Optical System

Nichols Research

SCI Inc.

Speedring, Inc.
Govemment Institutions

NASA Marshall Space Flight Center

U.S. Army Missile Command

Oak Ridge National Laboratory

National Institute of Standards \& Technology

\section{Advisory}

Space \& Systems Defense Command

Boeing

Mason and Hanger International

Morgan Research

Teledyne Brown Engineering

WIT, Inc. 


\section{Cumiculum Requirements}

\section{Hours Required Core Courses}

- 6 credit hours in Optics Principles:

(a) Geometrical Optics/(b) Physical Optics

- 9 credit hours in Optics Design and

Manufacturing Technology:

- Optics and Photonics Systems Design

- Optomechanical Design/Manufacturing

- Optical Fabrication and Testing

- 6 credit hours in Engineering Management: Integrated Production and Process

Design plus one course from area $\mathrm{k}$ or $\mathrm{l}$.

6 Hours Required in Elective Courses (two courses to be taken in one of the following lettered areas):

a. Optical Systems and Engineering

- Coherent Optical Systems/Holography

- Electro-Optical Engineering

- Optoelectronics

- Lens Design

- Non-Linear Optics

- Laser Electronics

- Introduction to Lasers

- Radiometry

b. Quantum Optics

- Quantum Optics

- Laser Physics

- Special Topics in Optics - Nonclassical States

- Quantum Mechanics for Optics and Solid State

- Lasers

- Optical Properties of Matter

c. Optical signals

- Random Signals and Noise

- Linear Systems

- Digital Image Processing

- Fourier Optics

- Signal Processing

- Special Topics in Optics - Optical Computing

d. Optical Communications

- Communication Theory

- Detection of Optical and Infrared Radiation

- Optical Communications

- Statistical Optics

- Fiber Optics

- Optical Phase Conjugation e. Optical Materials

- Elements of Material Science

- Crystal Physics and Crystal Growth

- Magnetic and Optical Properties of Materials

- Materials for Radiation Detectors

- Optical Properties of Matter

f. Manufacturing Technology, Systems

- Introduction to Systems Engineering

- Engineering Economic Analysis

g. Manufacturing Technology, Quality

- Statistical Quality Control

- Advanced Statistical Applications

i. Manufacturing Technology, Reliability

- Engineering Reliability

- Reliability, Availability, and Maintainability

j. Physics

- Introductory Quantum mechanics II

- Quantum Mechanics for Optics/Solid State

- Introduction to Solid State Physics I

- Classical Dynamics I

- Statistical Mechanics and Kinetic Theory I

k. Engineering Management Integrated

Production and Process

- Engineering Management Theory

- Foundations of Total Quality Management

- Financial Methods for Engineers

- Engineering Project Management

- Labor Relations for Engineers

- Organization Structure and Motivation

- Productivity and Quality Engineering

- Implementation of Technology

1. Marketing/Management/Management Science

- Introduction to Management of Technology

- Marketing - High Technology Environment

- Managing Technical Professionals

- New Product Development

- Marketing Emerging Technologies

6 Hours of On Site Practicum and Thesis required: 


\section{Typical Course Schedule}

\section{Fall Semester:}

- Geometrical Optics

- Physical Optics

- Engineering Management Elective

\section{Spring Semester.}

- Optics and Photonics System Design

- Optomechanical Design and Manufacturing

- Elective 1

\section{Summer:}

- On Site Practicum Thesis

Fall Semester.

- Integrated Product and Process Design

- Optical Fabrication and Testing

- Elective 2

\section{Optics and Photonics Systems Design}

\section{Course Outline:}

\section{Components}

1.1 Light Sources

1.2 Detectors

1.3 Modulators

1.4 Lenses and Mirrors

1.5 Diffractive Optical Elements

1.6 Fibers and Fiber Components

\section{Subsystems}

2.1 Transmitters

2.2 Receivers

2.3 Detector Arrays and Drive Electronics

2.4 Optical Correlators

2.5 Post Processing

\section{Systems}

3.1 Telescopes

3.2 Optical Pattern Recognition

3.3 Adaptive Signal Processing

3.4 Laser Radars

3.5 Infrared Systems

3.6 Fiber Communication Networks

3.7 Fiber Imaging

3.8 Fiber Sensors 


\section{Optomechanical Design and Manufacturing}

\section{Course Outline}

1. Optomechanics fundamentals and CAD

2. Optical mounts for mirrors, lenses, prisms \& filters

3. Adjustment mechanisms (linear, tilt and rotary)

4. Dimensional stability, thermal and environmental considerations

5. Material selection for optical and structural parts

6. Fabrication methods (tolerances, machining, HT \& chemical processes

7. Advanced topics (IR systems, DM optics, biomedical and environmental monitoring applications, optical methods for non-destructive testing)

8. Computer-aided design and analysis project

\section{Table VI}

\section{Optical Testing and Fabrication}

\section{Course Oudline}

1. Optical Bench Measurements Nodal Slide, focal lengths, cardinal points

2. Component measurements Radius of curvature, refractive index, surface roughness

3. General Light Field Measurements

4. Aberrations Wavefront aberrations, transverse aberrations, MTF

5. Geometrical Tests Knife-edge, Hartman, Ronchi

6. Interferometric and Wavefront Tests

Fizeau, Twyman-Green, lateral shearing,
7. Grinding and Polishing

8. Optical Coatings

9. Remote Optical Diagnostics Holographic interferometry, Moire tests

10. Fabrication and testing techniques of optical components and systems

11. Component measurements

12. Lecture and "Honds-on" Laboratory Grind and polish 8" f/10 mirror Test with WYCO, ZYGO, Foucault Reflective Coating 


\section{Table VII}

\section{Integrated Product and Process Design}

\section{Course Description:}

Introduces the concepts and tools which support integrated product and process design (IPPD). Particular attention will be paid to multi-functional teams and their value in promoting the concept of life-cycle engineering. Students will also gain experience with tools and technologies that support the IPPD philosophy and allow them to implement "real" product programs and to address the design-to-cost and performance issues that will arise.

\section{Course Outline:}

1. Introduction to the IPPD philosophy

2. Managing the Change to IPPD

3. Building Effective teams

4. Managing Multi-Functional Teams

5. Designing for Performance

6. Computer Aided Engineering \& Test Considerations

7. Design for Manufacturability
8. Design for Reliability \& Serviceability

9. Design for Testability

10. Design for Optimization

11. Program Cost and Schedule Development Issues

12. Project Management Issues Case Study

13. Implementation Case Studies 


\section{The MS/MSE Degree Program with Concentration in Optics and Photonics Technology \\ Samples of On-Site Practicum}

NASA Marshall Space Flight Center, Huntsville, AL

(a) Diamond Turning; (b) Ion Figuring; (c) Diffractive Optics; (d) Coherent Optics; (e) Video/Imaging Systems; (f) Optical Design

\section{U.S. Army Missile Command, Redstone Arsenal, AL}

(a) Guided Wave Optical Devices; (b) Integrated Optical Components; (c) Electro-Optical Polymer Devices; (d) icrofabrication for Electro-Optical Devices and Integration; (e) Diffractive and Binary Optics

\section{Oak Ridge National Laboratory, Oak Ridge, TN}

(a) Evaluation of prototype metrology instruments for optical scatter and figure; (b) Interpreting power spectrum measurements of deterministically fabricated surfaces; (c) Finite element analysis approaches to distortion-free mounting in fabrication, testing, and end-use; (d) Single point diamond turning; (e) Ion beam milling; (f) Ductile mode grinding of brittle materials; and (g) Selected topics in photonics.

National Institute of Standards \& Technology (NIST), Gaithersburg, MD

(a) Laser Ranging for Remote Sensing; (b) Ultrafast Lasers; (c) Absolute Cryogenic Radiometry; (d) Parametric Down Conversion; (e) Thermal Imaging

\section{Advanced Optical Systems, Huntsville, AL}

Optical Image Processing

Dynetics Inc., Huntsville, AL

Wideband High-Speed Signal Processing and Microwave Device Development based on Acousto-Optic Technology

\section{Hughes Danbury Optical Systems, Danbury, CT}

(a) White Light Interferometer for Coarse Metrology; (b) Caustic Scanning Interferometer for Testing Aspheric Optics

\section{Nichols Research Corporation, Huntsville, AL}

(a) Passive Ice Detection System for Flight Safety; (b) Advanced Optical Instrumentation

\section{SCI Systems, Humtsville, AL}

Fiber Position Sensor - Testing of the prototype of a high accouracy position sensor for fiber optic cable winding, perform additional analyses, and make design improvements.

\section{Speedring, Cullman, AL}

Precision Optical manufacturing 